\title{
Detection of Antiphosphatidylserine/Prothrombin Antibodies and Their Potential Diagnostic Value
}

\author{
Polona Žigon, ${ }^{1}$ Saša Čučnik, ${ }^{1}$ Aleš Ambrožič, ${ }^{1}$ Tanja Kveder, ${ }^{1}$ Snežna Sodin Šemrl, ${ }^{1,2}$ \\ Blaž Rozman, ${ }^{1}$ and Borut Božičc ${ }^{1,3}$ \\ ${ }^{1}$ Immunology Laboratory, Department of Rheumatology, University Medical Centre, 1000 Ljubljana, Slovenia \\ ${ }^{2}$ Faculty of Mathematics, Natural Science and Information Technology, University of Primorska, 6000 Koper, Slovenia \\ ${ }^{3}$ Faculty of Pharmacy, University of Ljubljana, 1000 Ljubljana, Slovenia \\ Correspondence should be addressed to Polona Žigon; polona.zigon@guest.arnes.si
}

Received 30 April 2013; Accepted 15 July 2013

Academic Editor: Guixiu Shi

Copyright (C) 2013 Polona Žigon et al. This is an open access article distributed under the Creative Commons Attribution License, which permits unrestricted use, distribution, and reproduction in any medium, provided the original work is properly cited.

Antiprothrombin antibodies, measured with phosphatidylserine/prothrombin complex (aPS/PT) ELISA, have been reported to be associated with antiphospholipid syndrome (APS). They are currently being evaluated as a potential classification criterion for this autoimmune disease, characterized by thromboses and obstetric complications. Given the present lack of clinically useful tests for the accurate diagnosis of APS, we aimed to evaluate in-house and commercial assays for determination of aPS/PT as a potential serological marker for APS. We screened 156 patients with systemic autoimmune diseases for antibodies against PS/PT, $\beta_{2}$-glycoprotein I, cardiolipin and for lupus anticoagulant activity. We demonstrated a high degree of concordance between the concentrations of aPS/PT measured with the in-house and commercial assays. Both assays performed comparably relating to the clinical manifestations of APS, such as arterial and venous thromboses and obstetric complications. IgG aPS/PT represented the strongest independent risk factor for the presence of obstetric complications, among all tested aPL. Both IgG and IgM aPS/PT were associated with venous thrombosis, but not with arterial thrombosis. Most importantly, the association between the presence of IgG/IgM aPS/PT and lupus anticoagulant activity was highly significant. Taken together, aPS/PT antibodies detected with the in-house or commercial ELISA represent a promising serological marker for APS and its subsets.

\section{Introduction}

Antiphospholipid syndrome (APS) is an autoimmune disease identified by clinical manifestations of vascular thromboses and obstetric complications, together with the serology of persistently positive antiphospholipid antibodies (aPL) [1,2]. aPL represent a heterogeneous group of immunoglobulins detected by coagulation tests, such as lupus anticoagulant activity (LA) or measured by an enzyme-linked immunosorbent assays (ELISAs) as anticardiolipin antibodies (aCL) or antibodies against $\beta_{2}$-glycoprotein I (anti- $\beta_{2}$ GPI).

Antiprothrombin antibodies have not yet been included in the classification criteria of APS, although they are emerging as an increasingly important supportive marker. In recent years, their association with APS was evaluated with contradictory outcomes. Some studies failed to reveal a significant association of antiprothrombin antibodies with manifestations of APS [3-6], yet in other studies, their correlation to APS was found. The possibility of antiprothrombin antibodies becoming an additional serological classification criterion for APS emerged, especially relevant in APS patients negative for classical aPL [7-10].

Antibodies recognizing prothrombin can be detected by ELISA targeting prothrombin alone, coated onto irradiated plates ( $\mathrm{aPT}$ ), or targeting the phosphatidylserine/prothrombin complex (aPS/PT). It was demonstrated that antibodies recognized prothrombin more efficiently in aPS/PT ELISA [11] and that aPS/PT correlated better with APS and LA activity $[7,8,12,13]$ as compared to aPT. The inclusion of aPS/PT, but not aPT, to the laboratory criteria for APS has been proposed [14]. The first published aPS/PT protocol [7] was later modified in our previous study [10] in order to 
increase the analytical sensitivity of the test. We have reported that our in-house aPS/PT ELISA was the most optimal method for the determination of all clinically relevant aPS/PT antibodies, exhibiting the highest percentage of LA activity, compared to aCL and anti- $\beta_{2}$ GPI $[10,15]$. We reported different avidity of antiprothrombin antibodies, as it is also known for several other autoimmune antibodies [16-18]. Moreover, we showed that the avidity was associated with their detection by different ELISAs.

Until recently, only some aPT commercial kits were available and they showed poor diagnostic sensitivity and specificity [6]. In 2010, the commercial QUANTA Lite aPS/PT IgG/IgM and LAC assays became available as an aid in the diagnosis of APS.

The lack of comparative analytical data between the various aPS/PT assays led the present investigation to compare our in-house aPS/PT ELISA with the commercial QUANTA Lite aPS/PT assay, in terms of diagnostic efficiency of aPS/PT. We aimed to determine whether the presence of aPS/PT antibodies was associated with specific clinical manifestation of APS and whether they could therefore become an additional serological marker of APS diagnosis. Additionally, our goal was to compare commercial kits enabling the detection of low avidity antiprothrombin antibodies, as was previously shown for our in-house aPS/PT ELISA [10].

\section{Materials and Methods}

2.1. Subjects. Sera from 156 of patients with systemic autoimmune diseases (34 males and 122 females, mean age 47 years, range 16-85) were analyzed in a cross-sectional study. APS, based on the revised International Consensus criteria [1], was diagnosed in 58 patients, APS associated with systemic lupus erythematosus (SLE) [19] in 38 patients. The control groups of patients were comprised of 24 patients with SLE, 25 patients with rheumatoid arthritis (RA) [20], and 11 Sjögren's syndrome patients (SS) [21]. Among all, 42 patients experienced an arterial event, 53 had a venous event, and 28 had obstetric complications (Table 1). The patients had their sera collected and analyzed when they were examined at the Department of Rheumatology (University Medical Centre, Ljubljana). This study was conducted as part of the National Research Program titled "Systemic Autoimmune Diseases" (number P3-0314). Participants signed an informed consent and the study was approved by the National Medical Ethics Committee, Ljubljana, Slovenia.

2.2. In-House aPS/PT ELISA. The levels of aPS/PT were detected according to the previously described aPS/PT ELISA protocol [10]. Medium binding plates (Costar, Cambridge, USA) were coated with phosphatidylserine in chloroform/methanol 1:4 and dried overnight at $4^{\circ} \mathrm{C}$. Following blocking with Tris-buffered saline (TBS) containing $1 \%$ bovine serum albumin (BSA) and $5 \mathrm{mM} \mathrm{CaCl}_{2}$ (1\% BSA/TBS-Ca), $25 \mu \mathrm{L}$ of human prothrombin (Enzyme Research Laboratories, Ltd., Swansea, UK) (20 mg/L) and $25 \mu \mathrm{L}$ of patients' sera diluted 1:50 were applied to wells immediately one after the other and incubated for $1 \mathrm{~h}$ at room temperature. After that, alkaline phosphatase-conjugated goat anti-human IgG or IgM (ACSC, Westbury, USA) were applied in TBS/Tween (0.05\% Tween) and incubated for $30 \mathrm{~min}$. Following 4 washes in TBS/Tween, $100 \mu \mathrm{L} /$ well of para-nitrophenylphosphate (Sigma Chemical Company, St. Louis, USA) in diethanolamine buffer ( $\mathrm{pH}$ 9.8) was applied and $\mathrm{OD}_{405}$ was kinetically measured by a spectrometer (Tecan Sunrise Remote, Grödig, Austria).

2.3. INOVA QUANTA Lite aPS/PT ELISA. A semiquantitative ELISA for the individual detection of IgG and IgM aPS/PT was performed following the manufacturer's instruction (INOVA Diagnostics, CA, USA).

2.4. INOVA QUANTA Lite LAC ELISA. A semiquantitative ELISA for the detection of both IgG and IgM aPS/PT class antibodies was performed following the manufacturer's instructions (INOVA Diagnostics, CA, USA).

2.5. aCL ELISA and Anti- $\beta_{2}$ GPI ELISA. IgG and IgM aCL were determined according to the previously described method [22, 23]. Anti- $\beta_{2}$ GPI were measured with our inhouse ELISA [24] and evaluated through the European forum for aPL [25].

2.6. Avidity Determination of IgG aPS/PT by Chaotropic $a P S / P T$ ELISA. The chaotropic aPS/PT ELISA with increased concentrations of $\mathrm{NaCl}$ during the antibody binding phase was used for avidity determination $[10,15]$. The presence of high avidity aPS/PT antibodies was identified when the binding of antibodies at $0.5 \mathrm{M} \mathrm{NaCl}$ remained higher than $70 \%$ of the initial binding at $0.136 \mathrm{M} \mathrm{NaCl}$. Low avidity aPS/PT antibodies were declared when the binding decreased $\leq 30 \%$ of the initial binding. The remaining samples were considered to be of heterogeneous avidity.

2.7. Lupus Anticoagulant. The assay was performed in blood samples collected in tubes containing $0.109 \mathrm{M}$ sodium citrate. Platelet-poor plasma was obtained by centrifugation at $2400 \mathrm{~g}$ for $20 \mathrm{~min}$ at $4^{\circ} \mathrm{C}$. After filtration, aliquots were stored at $-80^{\circ} \mathrm{C}$ until use. Clotting tests were performed using coagulation analyzer BCS Siemens according to the previous guidelines of the International Society on Thrombosis and Haemostasis ISTH [26]. Simplified Dilute Russell's Viper Venom Test (dRVVT) was performed using LA1 Screening reagent and LA2 Confirmatory reagent (Siemens) following the manufacturer's instructions [27]. A dRVVT ratio (LA1 screen/LA2 confirmation) above 1.2 was considered positive for LA activity. Activity of LA was quantified as follows: low positive (LA1/LA2 = 1.2-1.5), medium (LA1/LA2 = 1.5-2.0), and high positive (LA1/LA2 > 2.0).

2.8. Statistical Analysis. Statistical analysis was performed using the SPSS 15.0 program. Normal distribution was evaluated using descriptive statistic parameters, curve fittings, and Kolmogorov-Smirnov test. The Receiver Operating Characteristic (ROC) analysis and the area under the curve (AUC) 
TABLE 1: Prevalence of arterial thrombosis, venous thrombosis, and obstetric complications in the groups of selected autoimmune patients.

\begin{tabular}{|c|c|c|c|c|c|}
\hline & No. $(\mathrm{f} / \mathrm{m})$ & Arterial thrombosis (41) & Venous thrombosis (53) & Obstetric complications (28) & Total \\
\hline APS & $58(34 / 24)$ & $21(13 / 8)$ & $33(16 / 17)$ & 12 & \multirow{2}{*}{97} \\
\hline APS + SLE & $38(31 / 7)$ & $16(14 / 2)$ & $17(11 / 6)$ & 14 & \\
\hline SLE & $24(24 / 0)$ & $4(4 / 0)$ & $\mathbf{1}(1 / 0)$ & 1 & \multirow{3}{*}{60} \\
\hline RA & $25(22 / 3)$ & $\mathbf{0}$ & $2(2 / 0)$ & $\mathbf{0}$ & \\
\hline SS & $11(11 / 0)$ & $\mathbf{0}$ & $\mathbf{0}$ & 1 & \\
\hline
\end{tabular}

No.: number of patients, f/m: female/male, APS: antiphospholipid syndrome, RA: rheumatoid arthritis, SLE: systemic lupus erythematosus, and SS: Sjögren’s syndrome.

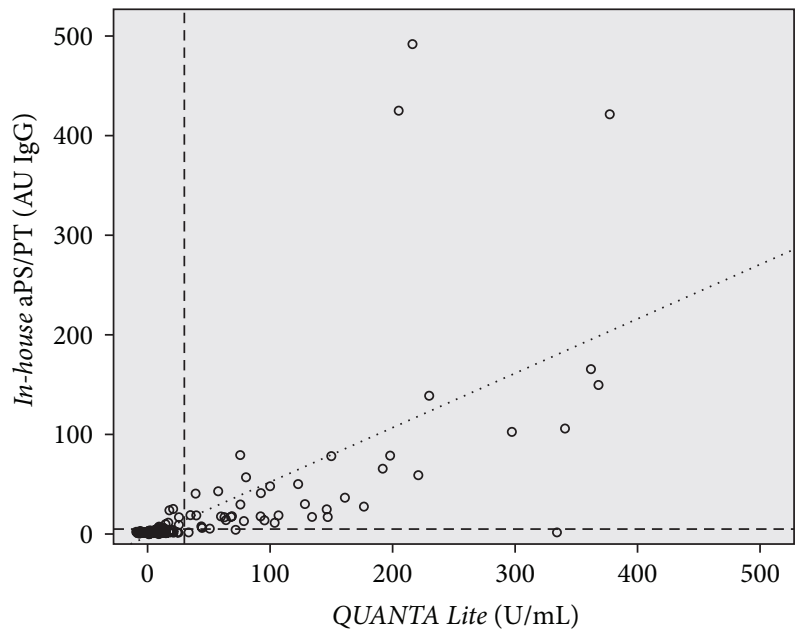

(a)

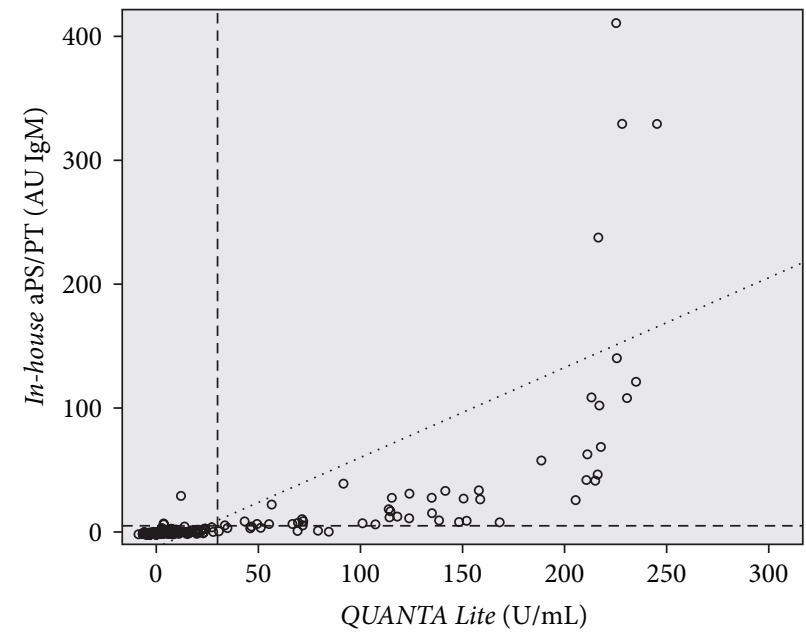

(b)

FIGURE 1: aPS/PT antibodies detected with the in-house ELISA correlated significantly with results of QUANTA Lite IgG (a) and IgM (b) in 156 patient sera. The dashed lines represent the cut-off value (in-house ELISA 5 AU, QUANTA Lite 30 U/mL). AU: arbitrary units.

were used to assess the diagnostic performance of the measured marker(s). The results of multivariate logistic models were approximated by odds ratio with its $95 \%$ confidence interval (OR (95\%)). A 2-sided $P$ value $<0.05$ was considered statistically significant.

\section{Results}

3.1. Correlation between In-House and QUANTA Lite aPS/PT Assays. Both IgG and IgM aPS/PT antibodies detected with in-house ELISA correlated significantly with results of QUANTA Lite immunoassays using Spearman correlation $($ rho $=0.744$ for IgG; rho $=0.865$ for IgM) (Figures $1(\mathrm{a})$ and $1(b))$ in 156 patient sera. Substantial concordance was validated also with Lin's concordance correlation coefficient $(\mathrm{Rc}=0.625$ for $\operatorname{IgG}$ and $\mathrm{Rc}=0.572$ for $\operatorname{IgM})$, which is a reproducibility measure.

\subsection{Diagnostic Applicability Comparison of Different} Antiphospholipid Antibody Assays. We evaluated APS diagnostic applicability of all assays with a receiver operating characteristic curve (ROC curve) and estimated the area under the curve (Figure 2). The highest diagnostic efficiency for APS was achieved by aCL IgG (AUC =0.88) (Figure 2(a)). Both, the in-house and the QUANTA Lite, IgG
aPS/PT methods were comparable (0.73 and 0.72, resp.). All methods detecting IgM aPL (Figure 2(b)) showed a lower overall performance compared to IgG aCL.

3.3. Relationship of aPL with Thrombosis and Obstetric Manifestations. The positivity of an individual aPL test and clinical manifestations of APS were considered in a logistic regression analysis (Table 2). IgG and IgM aPS/PT measured with the in-house and QUANTA Lite ELISA presented the highest independent risk factor for obstetric complication, among all tested $\mathrm{aPL}(\mathrm{OR}=9.3$ and $\mathrm{OR}=6.3$, resp., for $\mathrm{IgG}$ and IgM). Both IgG and IgM aPS/PT measured with either assay were an independent risk factor for the presence of venous thrombosis. However, the highest risk for venous thrombosis was achieved by LA $(\mathrm{OR}=5.6)$. IgG aPS/PT measured with QUANTA Lite ELISA were also an independent risk factor for the presence of arterial thrombosis, but the association was rather weak $(\mathrm{OR}=2.3, P=0.03)$.

The QUANTA Lite LAC screen test detected all sera positive in the individual IgG or IgM aPS/PT assays. The LAC screen did not achieve the diagnostic efficiency of the established LA coagulation test (Table 2).

3.4. Relationship between $L A$ and $a C L$, Anti- $\beta_{2} G P I$, or aPS/PT Antibodies. Out of 156 patients included in the study, 16 


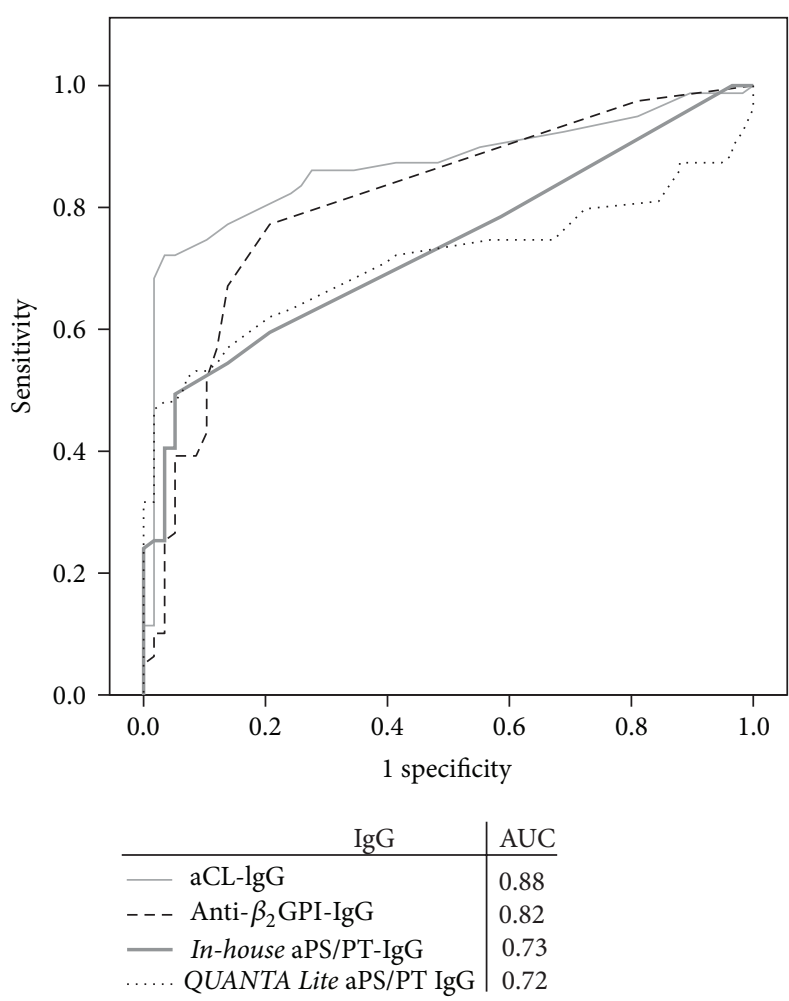

(a)

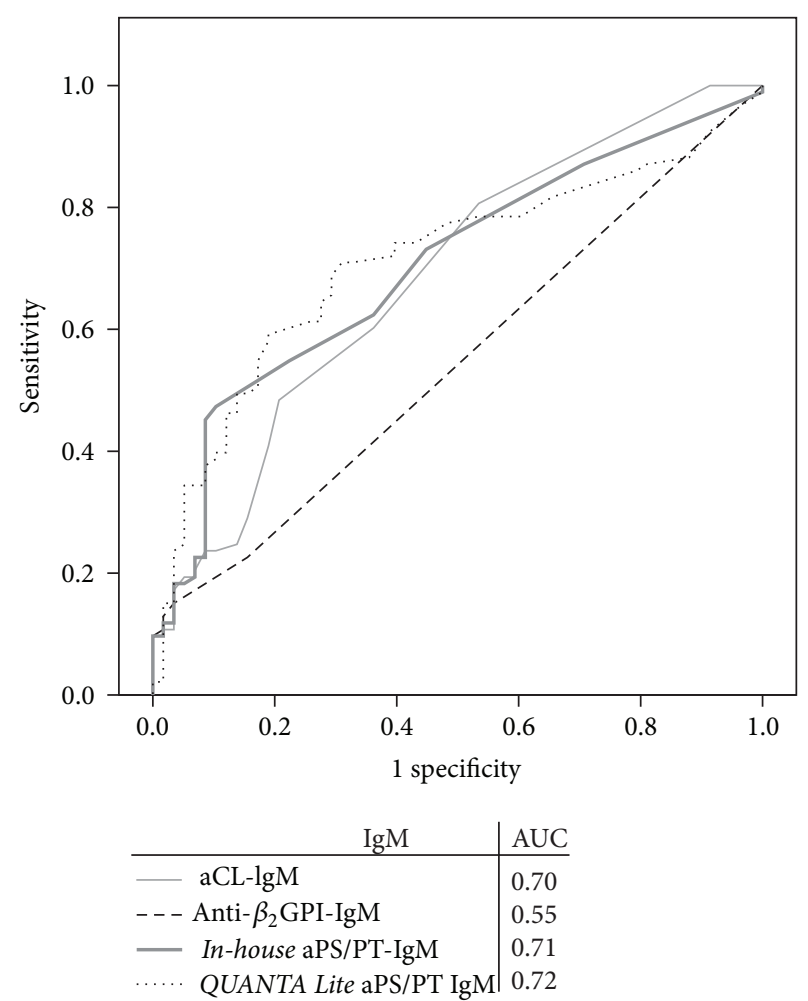

(b)

FIGURE 2: Receiver Operating Characteristic (ROC) curves and area under the curve (AUC) of different antiphospholipid antibody methods for APS $(n=156)$. The higher values of AUC indicate better diagnostic efficiency of the test. aCL: anticardiolipin, anti- $\beta_{2}$ GPI: anti$\beta_{2}$ glycoprotein, and aPS/PT antiphosphatidylserine/prothrombin.

(10\%) did not have their LA activity determined due to their anticoagulant treatment. Seven patients (3 APS, 3 RA, and 1 SS) were solely positive for LA, three of them had low, and four medium LA activity. Among all the aCL positive patients, $51 \%$ had LA; among the anti- $\beta_{2}$ GPI positive patients, $55 \%$ had LA, while among the aPS/PT positive patients, $66 \%$ had LA activity. aPS/PT, measured with either in-house or commercial assay, were much higher independent risk factors for the presence of LA activity (OR > 15.3 for IgG and OR > 12.9 for IgM) as compared to either aCL or anti- $\beta_{2}$ GPI (OR $<$ 9.0 for IgG and $\mathrm{OR}<4.6$ for IgM, resp.) (Table 3 ).

3.5. Avidity of aPS/PT. Avidity of IgG aPS/PT was determined using a chaotropic IgG aPS/PT ELISA in aPS/PT positive patients detected by the in-house IgG aPS/PT ELISA, regardless of the antibody level. Antibodies were detected of predominantly low, heterogeneous, and predominantly high avidity ( $n=9,33,9$ out of 51, resp.). Both the QUANTA Lite IgG aPS/PT ELISA and LAC screen assays detected more than $40 \%$ of sera with low avidity antibodies and more than $85 \%$ of those with heterogeneous or high avidity aPS/PT (Table 4).

Among nine patients with low avidity aPS/PT, seven were diagnosed with APS; three of which experienced arterial thrombosis, five venous thrombosis, and one had obstetric complications. Two out of 97 APS patients included in the study were positive in the QUANTA Lite IgG aPS/PT ELISA, but negative in the in-house aPS/PT ELISA and their avidity was not determined.

\section{Discussion}

A comprehensive comparative study of anti-prothrombin antibodies (on two in-house and three commercial aPT tests) conducted in 2007 by Tincani et al. reported issues with reproducibility and interpretation of results and advised against their routine use [6]. Antibodies against PS/PT were first described by Matsuda et al. in patients with LA in 1996 [28], while one year later, Galli et al. [11] reported that the aPS/PT assay was more sensitive than the aPT test. In 2000, Atsumi et al. pointed out that aPS/PT can be used not only to confirm the presence of LA, but also to serve (in addition to $\mathrm{aCL}$ and anti- $\beta_{2} \mathrm{GPI}$ ) as one of the markers of APS and also thrombotic events in patients with autoimmune diseases [7]. Since 2000, aPS/PT antibody detection stood the test of time and was proven as a useful tool for the diagnosis of APS [29]. Comparative studies gave additional indication of their diagnostic relevance and confirmed their closer correlation with APS and LA activity as compared to aPT $[7,8,13,30]$. The protocol by Matsuda et al. [12] used a higher concentration of phosphatidylserine $(65 \mu \mathrm{g} / \mathrm{mL})$ and prothrombin $(20 \mu \mathrm{g} / \mathrm{mL})$, while the protocols by Atsumi et al. [7], Tincani et al. [6], and Žigon et al. 
TABLE 2: Antiphospholipid antibodies and LA in a relationship to arterial thrombosis (AT), venous thrombosis (VT), and obstetric complications (OC).

\begin{tabular}{|c|c|c|c|c|c|c|}
\hline \multirow{2}{*}{ Antibody } & \multicolumn{6}{|c|}{ Arterial thrombosis (41) } \\
\hline & & No. & $P$ value & Odds ratio $(95 \% \mathrm{Cl})$ & Sensitivity \% & Specificity $\%$ \\
\hline LA & & 17 & 0.43 & $1.4(0.6-2.9)$ & 49 & 59 \\
\hline \multirow{2}{*}{$\mathrm{aCL}$} & $\operatorname{IgG}$ & 34 & $<0.001$ & $5.5(2.3-13.4)$ & 83 & 53 \\
\hline & $\operatorname{IgM}$ & 6 & 0.67 & $1.2(0.4-3.5)$ & 15 & 88 \\
\hline \multirow{2}{*}{ Anti- $\beta_{2}$ GPI } & $\operatorname{IgG}$ & 26 & 0.02 & $2.4(1.2-5.1)$ & 63 & 58 \\
\hline & $\operatorname{IgM}$ & 5 & 0.99 & $1.0(0.3-2.9)$ & 12 & 88 \\
\hline \multirow{3}{*}{ In-house aPS/PT } & IgG & 18 & 0.08 & $1.9(0.9-4.1)$ & 44 & 71 \\
\hline & $\operatorname{IgM}$ & 16 & 0.36 & $1.4(0.6-2.9)$ & 39 & 69 \\
\hline & IgG & 17 & 0.03 & $2.3(1.0-4.9)$ & 41 & 77 \\
\hline \multirow[t]{3}{*}{ QUANTA Lite aPS/PT } & $\operatorname{IgM}$ & 17 & 0.38 & $1.4(0.7-2.9)$ & 41 & 66 \\
\hline & LAC & 26 & 0.50 & $1.3(0.6-2.7)$ & 62 & 43 \\
\hline & \multicolumn{6}{|c|}{ Venous thrombosis (53) } \\
\hline LA & & 31 & $<0.001$ & $5.6(2.6-12.2)$ & 70 & 70 \\
\hline \multirow{2}{*}{$\mathrm{aCL}$} & IgG & 39 & $<0.005$ & $3.0(1.5-6.2)$ & 74 & 52 \\
\hline & $\operatorname{IgM}$ & 12 & 0.010 & $3.5(1.3-9.2)$ & 23 & 92 \\
\hline \multirow{2}{*}{ Anti- $\beta_{2}$ GPI } & IgG & 35 & $<0.001$ & $3.2(1.6-6.5)$ & 66 & 63 \\
\hline & $\operatorname{IgM}$ & 10 & 0.070 & $2.5(0.9-6.5)$ & 19 & 91 \\
\hline \multirow{2}{*}{ In-house aPS/PT } & $\operatorname{IgG}$ & 27 & $<0.001$ & $3.5(1.7-7.0)$ & 51 & 77 \\
\hline & $\operatorname{IgM}$ & 24 & 0.021 & $2.2(1.1-4.5)$ & 45 & 73 \\
\hline \multirow{4}{*}{ QUANTA Lite aPS/PT } & IgG & 25 & $<0.001$ & $4.0(1.9-8.3)$ & 47 & 82 \\
\hline & $\operatorname{IgM}$ & 26 & 0.013 & $2.4(1.2-4.7)$ & 49 & 71 \\
\hline & LAC & 37 & 0.043 & $2.1(1.0-4.2)$ & 70 & 47 \\
\hline & \multicolumn{6}{|c|}{ Obstetric complications (28) } \\
\hline LA & & 13 & $<0.005$ & $4.3(1.6-11.9)$ & 62 & 73 \\
\hline \multirow{2}{*}{$\mathrm{aCL}$} & IgG & 22 & $<0.001$ & $5.8(2.1-15.9)$ & 79 & 61 \\
\hline & $\operatorname{IgM}$ & 6 & 0.130 & $2.5(0.8-7.8)$ & 21 & 90 \\
\hline \multirow{2}{*}{ Anti- $\beta_{2}$ GPI } & $\operatorname{IgG}$ & 19 & 0.002 & $4.1(1.7-10.4)$ & 68 & 66 \\
\hline & $\operatorname{IgM}$ & 5 & 0.278 & $2.0(0.6-6.6)$ & 18 & 90 \\
\hline \multirow{3}{*}{ In-house aPS/PT } & $\operatorname{IgG}$ & 18 & $<0.001$ & $9.3(3.5-24.6)$ & 64 & 84 \\
\hline & $\operatorname{IgM}$ & 15 & $<0.005$ & $4.0(1.6-9.9)$ & 54 & 78 \\
\hline & $\operatorname{IgG}$ & 14 & $<0.001$ & $6.3(2.4-16.7)$ & 50 & 86 \\
\hline \multirow[t]{2}{*}{ QUANTA Lite aPS/PT } & $\operatorname{IgM}$ & 16 & $<0.005$ & $4.3(1.7-10.6)$ & 57 & 76 \\
\hline & LAC & 21 & 0.042 & $2.7(1.0-9.1)$ & 75 & 48 \\
\hline
\end{tabular}

aCL: anticardiolipin, anti- $\beta_{2}$ GPI: anti- $\beta_{2}$ glycoprotein, aPS/PT: anti-phosphatidylserine/prothrombin, LA: lupus anticoagulant, OR: odds ratio, and CI: confidence interval.

[10] all used lower concentrations of phosphatidylserine $(50 \mu \mathrm{g} / \mathrm{mL})$ and prothrombin $(10 \mu \mathrm{g} / \mathrm{mL})$. Additional major modifications between Matsuda et al. and later protocols are different times and temperatures of phosphatidylserine and prothrombin incubation. Recently, we have reported that our modified in-house aPS/PT ELISA (with increased analytical sensitivity) detects both presumably different populations of antibodies and low avidity antibodies, as well as it enables the identification of patients negative for other antiphospholipid antibodies [10]. The modification (by means of the concomitant antigen and antibody incubation) resulted in increased prothrombin concentration on phospholipid surface and possible exposure of additional epitopes on prothrombin, enabling a higher intensity of antiprothrombin antibody binding.
The current report shows that aPS/PT antibodies were the strongest independent risk factor for obstetric complications in our population of patients. Two previous studies on females with obstetric disorders found that aPS/PT antibodies were not frequent in patients with unexplained recurrent miscarriages without APS [5, 31]. However, in a recent study, comprising 163 women negative for the classical repertoire of aPL, antiprothrombin antibodies appeared to be associated with previous adverse pregnancy outcome [32]; however, the author did not support the potential use of these antibodies in clinical practice. In our study, among 28 female patients (26 were diagnosed with APS), IgG aPS/PT antibodies (measured by either in-house or commercial assay) showed the strongest correlation with obstetric complications, among all aPL antibodies. Further studies are warranted on a larger population 
TABLE 3: Association between the presence of antiphospholipid antibodies and LA activity.

\begin{tabular}{lccc}
\hline \multirow{2}{*}{ Antibody } & & \multicolumn{2}{c}{ Lupus anticoagulant activity } \\
& & $P$ value & Odds ratio $(95 \% \mathrm{Cl})$ \\
\hline \multirow{2}{*}{ aCL } & IgG & $<0.001$ & $5.0(2.4-10.6)$ \\
& IgM & $<0.001$ & $4.6(1.6-13.7)$ \\
Anti- $\beta_{2}$ GPI & IgG & $<0.001$ & $9.0(4.2-19.4)$ \\
& IgM & $<0.001$ & $1.2(1.0-1.4)$ \\
In-house aPS/PT & IgG & $<0.001$ & $\mathbf{2 1 . 6 ( 8 . 1 - 5 7 . 7 )}$ \\
& IgM & $<0.001$ & $12.9(5.4-30.6)$ \\
QUANTA Lite aPS/PT & IgG & $<0.001$ & $15.3(5.8-40.5)$ \\
& IgM & $<0.001$ & $13.2(5.6-30.8)$ \\
& LAC & $<0.001$ & $10.2(4.4-23.6)$ \\
\hline
\end{tabular}

aCL: anticardiolipin, anti- $\beta_{2}$ GPI: anti- $\beta_{2}$ glycoprotein, and aPS/PT: antiphosphatidylserine/prothrombin.

TABLE 4: Association of aPS/PT avidity with clinical features of autoimmune patients.

\begin{tabular}{|c|c|c|c|}
\hline aPS/PT avidity & $\begin{array}{c}\text { Low } \\
(n=9)\end{array}$ & $\begin{array}{l}\text { Heterogeneous } \\
\quad(n=33)\end{array}$ & $\begin{array}{l}\text { High } \\
(n=9)\end{array}$ \\
\hline APS & $7(77 \%)$ & $32(97 \%)$ & $9(100 \%)$ \\
\hline SLE & 2 & 1 & 0 \\
\hline RA & 0 & 0 & 0 \\
\hline SS & 0 & 0 & 0 \\
\hline Thrombosis & 8 & 26 & 8 \\
\hline Arterial & 3 & 11 & 4 \\
\hline Venous & 5 & 10 & 5 \\
\hline Obstetric disorder & 1 & 14 & 4 \\
\hline \multicolumn{4}{|l|}{ aPS/PT positivity } \\
\hline In-house IgG aPS/PT & 9 & 33 & 9 \\
\hline QUANTA Lite IgG aPS/PT & 4 & 29 & 8 \\
\hline QUANTA Lite LAC & 7 & 32 & 9 \\
\hline
\end{tabular}

APS: antiphospholipid syndrome, SLE: systemic lupus erythematosus, RA: rheumatoid arthritis, SS: Sjögren's syndrome, and aPS/PT: antiphosphatidylserine/prothrombin antibodies.

of obstetric patients. Taking into account the logistic regression results, $\mathrm{IgG} / \mathrm{IgM}$ aPS/PT were also independent risk factors for the presence of venous thrombosis $(\mathrm{OR}=3.5$ and $\mathrm{OR}=2.2$, resp.). The highest $\mathrm{OR}$ for venous thrombosis is presented by LA $(\mathrm{OR}=5.6)$, while all of the measured aPL showed statistically significantly correlation. On the other hand, aPS/PT antibodies were not strong independent risk factor for arterial thrombosis. Similarly, Vlagea et al. found no association between the presence of aPS/PT and arterial thrombosis [33]. Two previous studies [7, 8] have shown anti-prothrombin antibodies as an independent risk factor for arterial thrombosis, but other reports $[6,9,34]$ presented their data without differentiating between arterial or venous thromboembolic events. In general, all IgM antibody subtypes of aPL demonstrated a lower diagnostic efficiency for thrombosis as compared to IgG aPL. These data are in line with the results of a systematic review [35] and a later study [36] which reported IgM aCL, anti- $\beta_{2}$ GPI, and anti-prothrombin antibodies to be less often associated with clinical events of APS than IgG.

Correlation between aPS/PT and LA activity has been reported previously $[7,13,33,37]$ and our current study confirmed a strong correlation between aPS/PT and LA activity. IgG/IgM aPS/PT were the highest independent risk factors for LA activity with an OR $>12.9$ as compared to $\mathrm{aCL}$ and anti- $\beta_{2}$ GPI with an OR $<9.0$. Despite internationally accepted guidelines and many efforts to improve the standardization of LA activity assays, accurate detection and intralaboratory reproducibility are still not fully achieved. LA determination is a sequential series of analyses, which requires careful treatment of plasma specimens obtained from patients who are not receiving any anticoagulant therapy. So, the aPS/PT assay could represent a solid additional test performed using sera samples of patients regardless of anticoagulant therapy.

Very few studies have reported on the avidity of antiprothrombin antibodies. Avidity was shown to importantly influence positivity in different antiprothrombin ELISAs given that none of the low avidity antibodies were positive in the aPT ELISA [15]. On the contrary, aPS/PT assay enables the detection of low avidity antibodies, as evidenced in the current report. Our in-house IgG aPS/PT detected 9 positive patients with low avidity; however, QUANTA Lite IgG aPS/PT assay detected only $40 \%$ of low avidity anti-prothrombin antibodies. (Table 4). Our group has previously shown that avidity of anti- $\beta_{2}$ GPI importantly correlated with the clinical onset; therefore, it appeared reasonable to assume the same for the avidity of antiprothrombin antibodies [16]. However, we could not draw the same conclusion, but found that out of nine patients with low avidity aPS/PT antibodies, seven had APS. Therefore, a method enabling the detection of low avidity aPS/PT is also essential for possible inclusion of aPS/PT in the classification criteria for APS.

In conclusion, the present study is in line with the recommendations advising confirmation of previous data for "noncriteria aPL," such as aPS/PT [38]. The only commercially available aPS/PT assay was evaluated in comparison to our in-house aPS/PT. aPS/PT detected with either in-house aPS/PT ELISA or with QUANTA Lite aPS/PT ELISA showed very high specificity for APS that could serve as an additional serological diagnostic marker for venous thrombosis and obstetric complications. The association of aPS/PT with LA activity was the highest among all aPL tested and therefore can be a useful feature of these antibodies. In summary, aPS/PT, measured with either in-house or commercial assay, in addition to aCL and anti- $\beta_{2}$ GPI antibodies, could represent an additional marker in patients with clinical manifestations of APS.

\section{Abbreviations}

Anti- $\beta_{2}$ GPI: Antibodies against $\beta_{2}$-glycoprotein I

aCL: Anti-cardiolipin antibodies

APS: Antiphospholipid syndrome

aPS/PT: Phosphatidylserine-dependent anti-prothrombin antibodies

aPT: Antibodies against prothrombin alone 
AUC: Area under the curve

CI: Confidence interval,

LA: Lupus anticoagulant

OR: Odds ratio

PS: Phosphatidylserine

RA: Rheumatoid arthritis

ROC: Receiver operating characteristic

SLE: Systemic lupus erythematosus

SS: Sjögren's syndrome.

\section{Conflict of Interests}

The authors state that there is no conflict of interests.

\section{Acknowledgments}

This work was supported by the Ministry of High Education, Science and Technology of Slovenia (National Research Program number P3-0314). The authors thank INOVA Diagnostics Inc., San Diego, USA, as well as their German and Slovenian distributors for kindly providing their products.

\section{References}

[1] S. Miyakis, M. D. Lockshin, T. Atsumi et al., "International consensus statement on an update of the classification criteria for definite antiphospholipid syndrome (APS)," Journal of Thrombosis and Haemostasis, vol. 4, no. 2, pp. 295-306, 2006.

[2] W. A. Wilson, A. E. Gharavi, T. Koike Lockshin MD et al., "International consensus statement on preliminary classification criteria for definite antiphospholipid syndrome: report of an international workshop," Arthritis \& Rheumatism, vol. 42, no. 7, pp. 1309-1311, 1999.

[3] N. Bardin, M. C. Alessi, F. Dignat-George et al., "Does the anti-prothrombin antibodies measurement provide additional information in patients with thrombosis?" Immunobiology, vol. 212, no. 7, pp. 557-565, 2007.

[4] M. Galli, "Anti-prothrombin antibodies," in The Antiphospholipid Syndrome II, R. A. Asherson, R. Cervera, J. C. Piette, and Y. Shoenfeld, Eds., pp. 59-70, Elsevier, New York, NY, USA, 2002.

[5] M. Sugiura-Ogasawara, T. Atsumi, Y. Ozaki, T. Koike, and K. Suzumori, "Phosphatidylserine-dependent antiprothrombin antibodies are not useful markers for high-risk women with recurrent miscarriages," Fertility and Sterility, vol. 82, no. 5, pp. 1440-1442, 2004.

[6] A. Tincani, G. Morozzi, A. Afeltra et al., "Antiprothrombin antibodies: a comparative analysis of homemade and commercial methods. A collaborative study by the Forum Interdisciplinare per la Ricerca nelle Malattie Autoimmuni (FIRMA)," Clinical and Experimental Rheumatology, vol. 25, no. 2, pp. 268-274, 2007.

[7] T. Atsumi, M. Ieko, M. L. Bertolaccini et al., "Association of autoantibodies against the phosphatidylserine-prothrombin complex with manifestations of the antiphospholipid syndrome and with the presence of lupus anticoagulant," Arthritis \& Rheumatism, vol. 43, no. 9, pp. 1982-1993, 2000.

[8] M. L. Bertolaccini, T. Atsumi, T. Koike, G. R. V. Hughes, and M. A. Khamashta, "Antiprothrombin antibodies detected in two different assay systems. Prevalence and clinical significance in systemic lupus erythematosus," Thrombosis and Haemostasis, vol. 93, no. 2, pp. 289-297, 2005.
[9] A. Ghirardello, N. Bizzaro, S. Zampieri et al., "Biological and clinical relevance of anti-prothrombin antibodies," Annals of the New York Academy of Sciences, vol. 1109, pp. 503-510, 2007.

[10] P. Žigon, A. Ambrožič, S. Čučnik, T. Kveder, B. Rozman, and B. Božič, "Modified phosphatidylserine-dependent antithrombin ELISA enables identification of patients negative for other antiphospholipid antibodies and also detects low avidity antibodies," Clinical Chemistry and Laboratory Medicine, vol. 49, no. 6, pp. 1011-1018, 2011.

[11] M. Galli, G. Beretta, M. Daldossi, E. M. Bevers, and T. Barbui, "Different anticoagulant and immunological properties of antiprothrombin antibodies in patients with antiphospholipid antibodies," Thrombosis and Haemostasis, vol. 77, no. 3, pp. 486-491, 1997.

[12] J. Matsuda, T. Sanaka, A. Nishizawa, M. Gotoh, and K. Gohchi, "Two antiprothrombin antibodies against prothrombin and prothrombin-phosphatidyl serine show partial but not total identity," Blood Coagulation and Fibrinolysis, vol. 13, no. 8, pp. 697-702, 2002.

[13] J. Nojima, Y. Iwatani, E. Suehisa, H. Kuratsune, and Y. Kanakura, "The presence of anti-phosphatidylserine/prothrombin antibodies as risk factor for both arterial and venous thrombosis in patients with systemic lupus erythematosus," Haematologica, vol. 91, no. 5, pp. 699-702, 2006.

[14] T. Atsumi and T. Koike, "Antiprothrombin antibody: why do we need more assays?” Lupus, vol. 19, no. 4, pp. 436-439, 2010.

[15] P. Žigon, S. Čučnik, A. Ambrožič, S. S. Šemrl, T. Kveder, and B. Božičc, "Antibodies to phosphatidylserine/prothrombin complex as an additional diagnostic marker of APS?" Lupus, vol. 21, no. 7, pp. 790-792, 2012.

[16] S. Čučnik, T. Kveder, I. Križaj, B. Rozman, and B. Božič, "High avidity anti- $\beta 2$-glycoprotein I antibodies in patients with antiphospholipid syndrome," Annals of the Rheumatic Diseases, vol. 63, no. 11, pp. 1478-1482, 2004.

[17] W. Lin, M. Chen, and M.-H. Zhao, "Follow-up of avidity and titer of anti-myeloperoxidase antibodies in sera from patients with primary ANCA-associated vasculitis," Autoimmunity, vol. 42, no. 3, pp. 198-202, 2009.

[18] P. Suwannalai, H. U. Scherer, D. Van Der Woude et al., "Anticitrullinated protein antibodies have a low avidity compared with antibodies against recall antigens," Annals of the Rheumatic Diseases, vol. 70, no. 2, pp. 373-379, 2011.

[19] M. C. Hochberg, "Updating the American College of Rheumatology revised criteria for the classification of systemic lupus erythematosus," Arthritis \& Rheumatism, vol. 40, no. 9, article $1725,1997$.

[20] F. C. Arnett, S. M. Edworthy, D. A. Bloch et al., "The American Rheumatism Association 1987 revised criteria for the classification of rheumatoid arthritis," Arthritis \& Rheumatism, vol. 31, no. 3, pp. 315-324, 1988.

[21] C. Vitali, S. Bombardieri, R. Jonsson et al., "Classification criteria for Sjögren's syndrome: a revised version of the European criteria proposed by the American-European Consensus Group," Annals of the Rheumatic Diseases, vol. 61, no. 6, pp. 554558, 2002.

[22] B. Božič, T. Kveder, M. Stegnar et al., "Influence of degraded phosphatidylserine on binding of antiphospholipid antibodies," International Archives of Allergy and Immunology, vol. 112, no. 1, pp. 19-26, 1997.

[23] S. Loizou, J. D. McCrea, and A. C. Rudge, "Measurement of anticardiolipin antibodies by an enzyme-linked immunosorbent 
assay (ELISA): standardization and quantitation of results," Clinical and Experimental Immunology, vol. 62, no. 3, pp. 738745, 1985.

[24] S. Čučnik, A. Ambrožič, B. Božič, M. Skitek, and T. Kveder, "Anti- $\beta 2$-glycoprotein I ELISA: methodology, determination of cut-off values in 434 healthy Caucasians and evaluation of monoclonal antibodies as possible international standards," Clinical Chemistry and Laboratory Medicine, vol. 38, no. 8, pp. 777-783, 2000.

[25] G. Reber, I. Schousboe, A. Tincani et al., "Inter-laboratory variability of anti- $\beta 2$-glycoprotein I measurement: a Collaborative Study in the Frame of the European Forum on Antiphospholipid Antibodies Standardization Group," Thrombosis and Haemostasis, vol. 88, no. 1, pp. 66-73, 2002.

[26] J. T. Brandt, D. A. Triplett, B. Alving, and I. Scharrer, "Criteria for the diagnosis of lupus anticoagulants: an update. On behalf of the Subcommittee on Lupus Anticoagulant/Antiphospholipid Antibody of the Scientific and Standardisation Committee of the ISTH," Thrombosis and Haemostasis, vol. 74, no. 4, pp. 1185-1190, 1995.

[27] T. Exner, G. Papadopoulos, and J. Koutts, "Use of a simplified dilute Russell's viper venom time (DRVVT) confirms heterogeneity among 'lupus anticoagulants,' Blood Coagulation. Fibrinolysis, vol. 1, no. 3, pp. 259-266, 1990.

[28] J. Matsuda, N. Saitoh, M. Gotoh, K. Kawasugi, K. Gohchi, and M. Tsukamoto, "Phosphatidyl serine-dependent antiprothrombin antibody is exclusive to patients with lupus anticoagulant," British Journal of Rheumatology, vol. 35, no. 6, pp. 589-591, 1996.

[29] T. Atsumi, O. Amengual, S. Yasuda, and T. Koike, "Antiprothrombin antibodies-are they worth assaying?" Thrombosis Research, vol. 114, no. 5-6, pp. 533-538, 2004.

[30] A. Tsutsumi, T. Hayashi, Y. Chino et al., "Significance of antiprothrombin antibodies in patients with systemic lupus erythematosus: clinical evaluation of the antiprothrombin assay and the antiphosphatidylserine/prothrombin assay, and comparison with other antiphospholipid antibody assays," Modern Rheumatology, vol. 16, no. 3, pp. 158-164, 2006.

[31] A. Tsutsumi, T. Atsumi, H. Yamada et al., "Antiphosphatidylserine/prothrombin antibodies are not frequently found in patients with unexplained recurrent miscarriages," American Journal of Reproductive Immunology, vol. 46, no. 3, pp. 242-244, 2001.

[32] L. Marozio, A. Curti, G. Botta et al., "Anti-prothrombin antibodies are associated with adverse pregnancy outcome," American Journal of Reproductive Immunology, vol. 66, no. 5, pp. 404-409, 2011.

[33] A. Vlagea, A. Gil, M. V. Cuesta et al., "Antiphosphatidylserine/Prothrombin antibodies (aPS/PT) as potential markers of antiphospholipid syndrome," Clinical and Applied Thrombosis/Hemostasis, vol. 19, no. 3, pp. 289-296, 2012.

[34] T. D. Jaskowski, A. R. Wilson, H. R. Hill, W. D. Branch, and A. E. Tebo, "Autoantibodies against phosphatidylserine, prothrombin and phosphatidylserine-prothrombin complex: identical or distinct diagnostic tools for antiphospholipid syndrome?" Clinica Chimica Acta, vol. 410, no. 1-2, pp. 19-24, 2009.

[35] M. Galli, D. Luciani, G. Bertolini, and T. Barbui, "Anti- $\beta 2$ glycoprotein I, antiprothrombin antibodies, and the risk of thrombosis in the antiphospholipid syndrome," Blood, vol. 102, no. 8, pp. 2717-2723, 2003.

[36] M. Galli, G. Borrelli, E. M. Jacobsen et al., "Clinical significance of different antiphospholipid antibodies in the WAPS (warfarin in the antiphospholipid syndrome) study," Blood, vol. 110, no. 4, pp. 1178-1183, 2007.

[37] Y. Sakai, T. Atsumi, M. Ieko et al., "The effects of phosphatidylserine-dependent antiprothrombin antibody on thrombin generation," Arthritis and Rheumatism, vol. 60, no. 8, pp. 2457-2467, 2009.

[38] M. L. Bertolaccini, O. Amengual, T. Atsumi et al., "Non-criteria' aPL tests: report of a task force and preconference workshop at the 13th International Congress on Antiphospholipid Antibodies, Galveston, TX, USA, April 2010," Lupus, vol. 20, no. 2, pp. 191-205, 2011. 


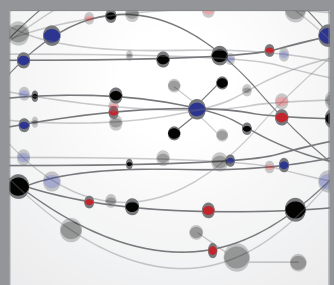

The Scientific World Journal
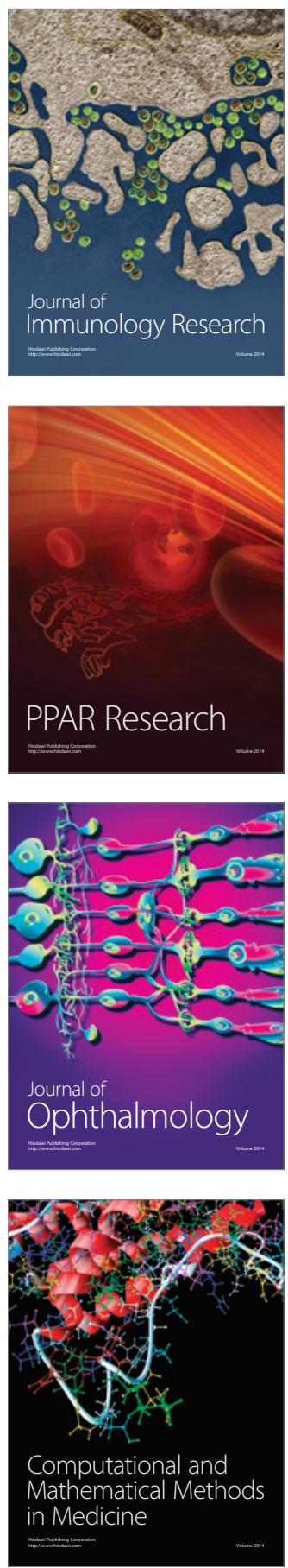

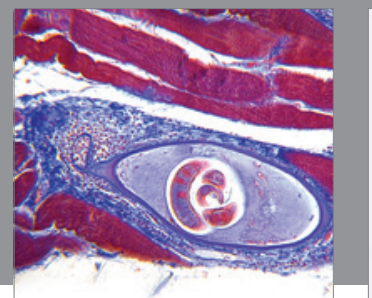

Gastroenterology

Research and Practice
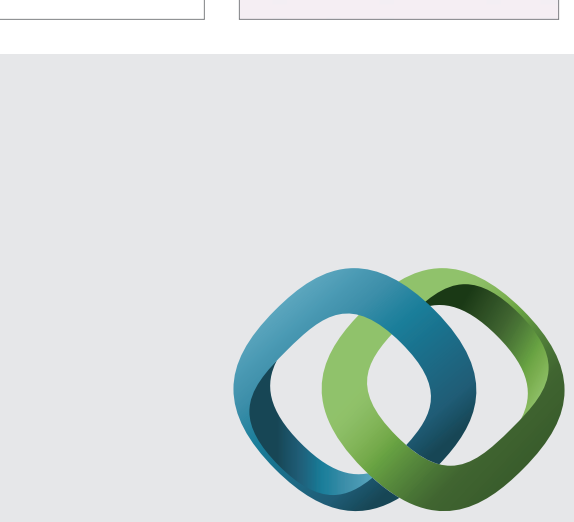

\section{Hindawi}

Submit your manuscripts at

http://www.hindawi.com
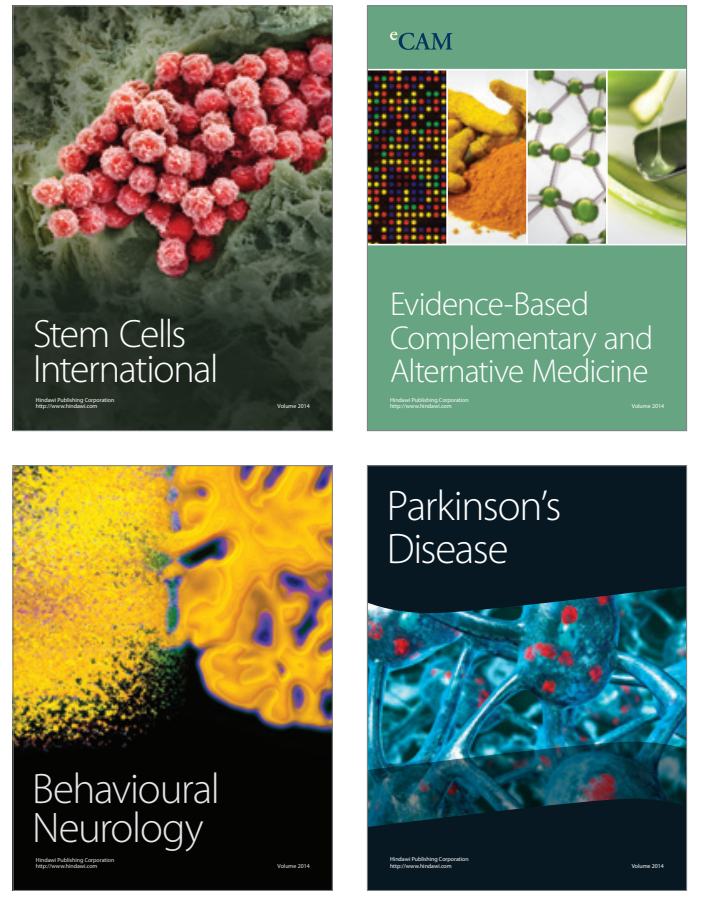
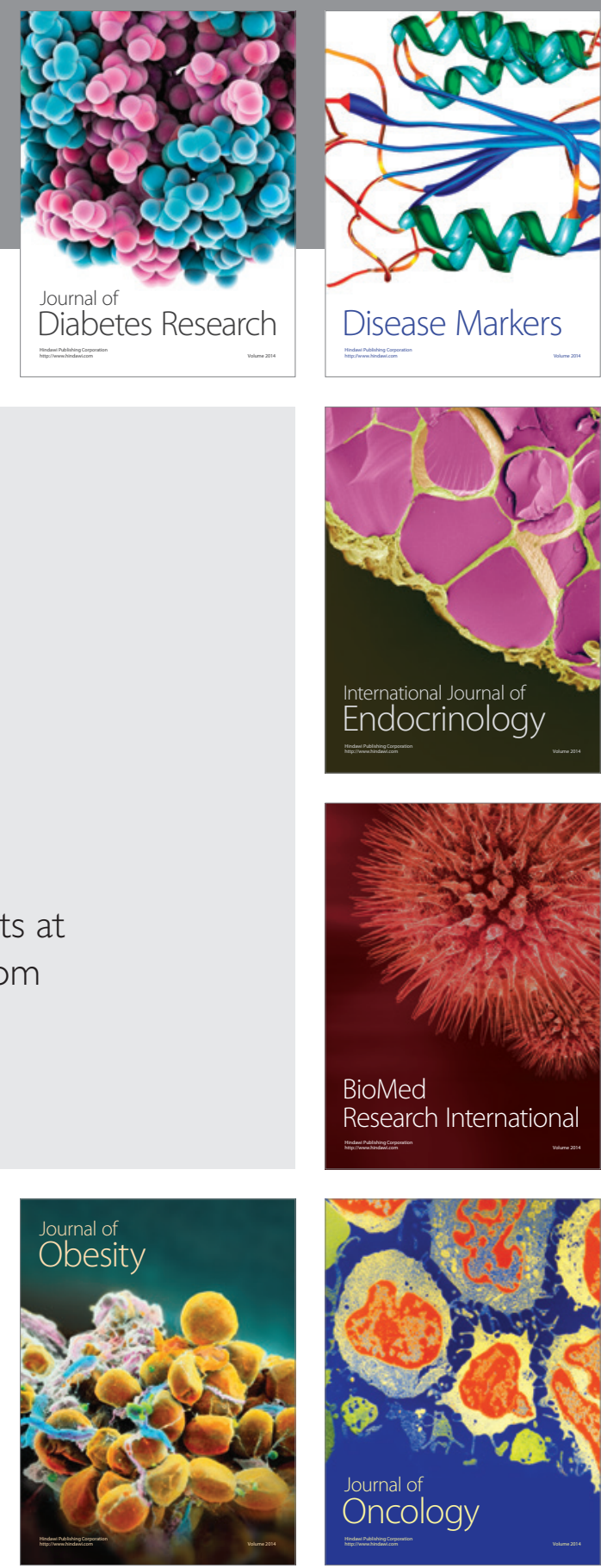

Disease Markers
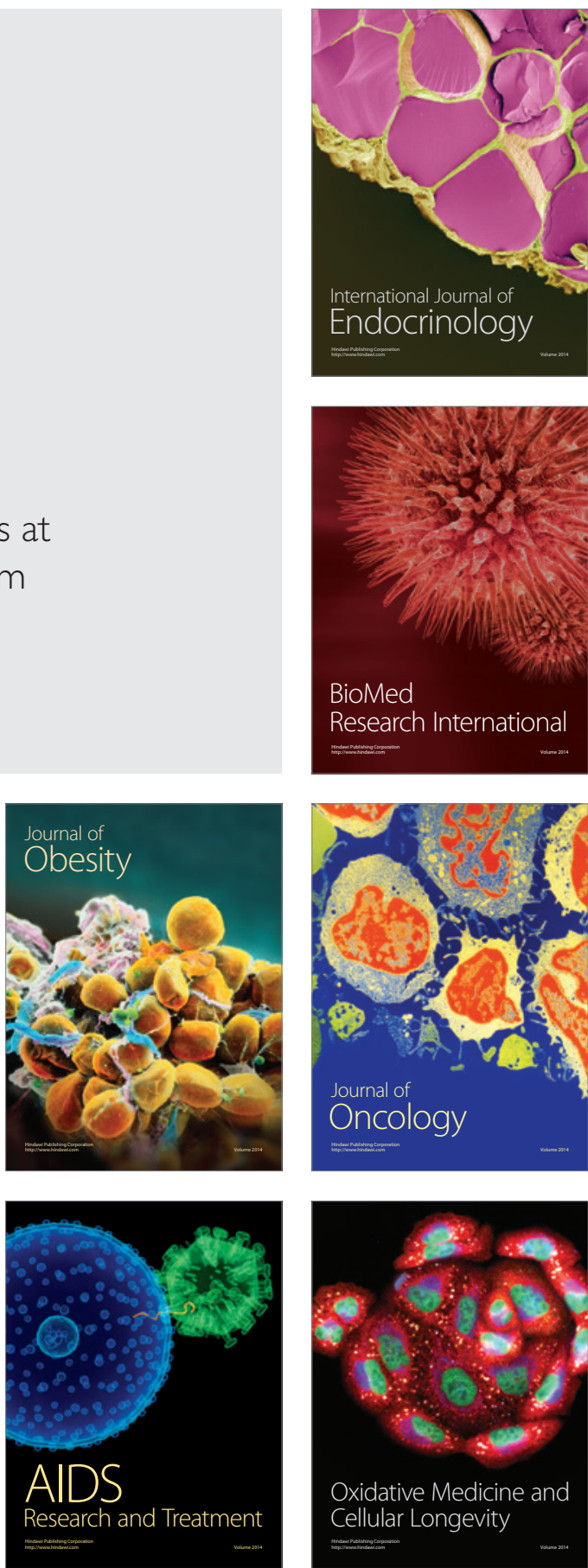